\title{
Isolation and Identification of a Phosphate Deficiency-Induced C-Glycosylflavonoid That Stimulates Arbuscular Mycorrhiza Formation in Melon Roots
}

\author{
Kohki Akiyama, Hiroyuki Matsuoka, and Hideo Hayashi \\ Natural Products Chemistry, Division of Applied Biological Chemistry, Graduate School of Agriculture \\ and Biological Sciences, Osaka Prefecture University, Sakai, Osaka 599-8531, Japan
}

Submitted 30 July 2001. Accepted 6 December 2001.

\begin{abstract}
Melon (Cucumis melo) roots were inoculated with or without the arbuscular mycorrhizal (AM) fungus Glomus caledonium under low phosphate conditions. High-performance liquid chromatography analysis of the secondary metabolites in butanol extracts from roots revealed that the level of one compound in noninoculated roots showed a significant increase from 30 days postinoculation. No accumulation was observed in mycorrhizal roots and high-phosphatesupplemented roots, indicating that the accumulation of the compound was caused by a phosphate deficiency. The compound was isolated by column chromatography and identified by spectroscopic methods to be a $\boldsymbol{C}$-glycosylflavone, isovitexin $2^{\prime \prime}-O-\beta$-glucoside. The effect of the compound on mycorrhizal colonization in melon roots was examined under low $(0.05 \mathrm{mM})$ and high $(2 \mathrm{mM})$ phosphate conditions. The degree of mycorrhizal colonization in control roots grown under high phosphate conditions $(\mathbf{8 . 8 \%})$ was much lower than when grown under low phosphate conditions $(22 \%)$. The treatment of roots with the compound at concentrations of 20 and $50 \mu \mathrm{M}$ increased root colonization under both low and high phosphate conditions. In particular, the degrees of mycorrhizal colonization in treated roots grown under high phosphate conditions ( 25 and $22 \%$ at 20 and $50 \mu \mathrm{M}$, respectively) were comparable to that in untreated control roots grown under low phosphate conditions $(22 \%)$. These findings suggest that the phosphate deficiency-induced $\boldsymbol{C}$-glycosylflavonoid is involved in the regulation of $\mathrm{AM}$ fungal colonization in melon roots.
\end{abstract}

Arbuscular mycorrhiza is the most widespread form of symbiotic associations between soilborne fungi in the order Glomales and plant roots. This symbiosis confers benefits to the host plant's growth and development through the acquisition of phosphate and minerals from the soil by the fungi. In addition, it enhances the plant's resistance to pathogens and environmental stresses (Gianinazzi-Pearson 1996; Harrison 1999). It has been calculated that the arbuscular mycorrhizal (AM) fungi are able to colonize the roots of $80 \%$ of terrestrial plants. Recent observations of fossils from the Ordovician era suggest that Glomales-like fungi were present at a time when the land flora most likely consisted only of plants on the bryophytic level, suggesting that the fungi played a crucial role in facilitat-

Corresponding author: K. Akiyama; Telephone: +81-722-54-9472; Fax: +81-722-54-9471; E-mail: akiyama@ biochem.osakafu-u.ac.jp ing the colonization of land by plants (Redecker et al. 2000). Despite the ubiquitous occurrence of this symbiosis and its importance in sustainable agriculture, the mechanisms for the formation of a functional symbiosis between plants and AM fungi are almost entirely unknown. A major factor hampering studies on the AM fungi is their obligately biotrophic nature; so far, the fungi have not been cultured in the absence of a plant host. However, recent studies based on molecular, genetic, and biochemical techniques are rapidly accumulating information about AM symbiosis (Harrison 1999).

There is increasing evidence that colonization of plant roots by AM fungi induces quantitative and qualitative changes of secondary metabolites in the plants. These compounds inside the roots and released by the roots are hypothesized to play an important role in the regulation of AM symbiosis. In Medicago truncatula and alfalfa roots, isoflavonoid biosynthesis leading to phytoalexin medicarpin production is transiently activated during early stages of colonization and then subsequently suppressed (Harrison and Dixon 1993). Some flavonoids and phenolic compounds have been shown to stimulate the spore germination and hyphal growth of AM fungi (Vierheilig et al. 1998). Isoflavonoids, formononetin and biochanin A, were isolated from phosphate-deprived clover roots as active compounds capable of stimulating AM hyphal growth (Nair et al. 1991). Interestingly, the isoflavones promoted mycorrhizal colonization in many plant species when applied into the soil (Siqueira et al. 1991; Vierheilig et al. 1998). Other types of flavonoids such as apigenin, coumestrol, and daidzein also increased root colonization of soybean by the AM fungus Glomus mosseae (Xie et al. 1995). The mevalonate-independent methylerythritol phosphate (MEP) pathway was induced by the AM fungal colonization of wheat and maize roots, resulting in the accumulation of various isoprenoid cyclohexenone derivatives and an acyclic polyene mycorradicin (Walter et al. 2000). In contrast to the flavonoids, application of blumenin, one of the major constituents among the cyclohexenone derivatives, strongly inhibited fungal colonization and arbuscule formation at early stages of mycorrhiza development (Fester et al. 1999). These findings suggest that plant secondary metabolites might act as regulators in a plant-AM fungus interaction during the precolonization stage and the cell-to-cell stage.

In order to better understand the role of secondary metabolites in the development and regulation of AM symbiosis, we have recently started to identify plant secondary metabolites that show a significant change in their levels during arbuscular mycorrhiza formation. So far, the levels of two novel and one 
known triterpenoids were found to increase upon mycorrhizal colonization of cucumber roots (Akiyama and Hayashi, in press). In this study, melon roots were examined for secondary metabolite changes during AM fungal colonization. It was found that the level of a $C$-glycosylflavone, identified as isovitexin $2^{\prime \prime}$ - $O$ - $\beta$-glucoside, significantly increased in noninoculated control roots grown under phosphate-limited conditions and that the flavonoid significantly stimulated mycorrhizal colonization in melon roots grown under low and high phosphate conditions.

\section{RESULTS}

Plant growth, mycorrhizal colonization, and high-performance liquid chromatography (HPLC) analysis of melon root extracts.

The degree of mycorrhizal colonization of melon roots by $G$. caledonium showed a consistent increase. The percentages of mycorrhizal colonization in the inoculated roots were 2.5, 5.0, 12 , and $17 \%$ at 10, 20, 30, and 40 days postinoculation, respectively. No colonization was observed in noninoculated control roots that received a $53-\mu \mathrm{m}$ sievate of the inoculum. There was no marked difference in growth between G. caledonium-inoculated plants and phosphate-supplemented ones through the time course experiments. In contrast, control plants grown under phosphate-limited conditions exhibited growth similar to the inoculated plants up to 20 days postinoculation, but the growth was gradually retarded thereafter.

HPLC analysis of ethyl acetate and butanol extracts from melon roots at 40 days postinoculation revealed a significant accumulation of one compound in the butanol extracts from control roots (Fig. 1). The levels of the compound were very low in both mycorrhizal roots and phosphate-supplemented roots, indicating that the accumulation was caused by a phosphate deficiency.

\section{Structure elucidation}

of the phosphate deficiency-induced compound.

The compound was isolated by column chromatography from melon roots grown under phosphate-limited conditions and was subjected to spectroscopic analysis. Positive-ion fast atom bombardment (FAB) mass spectrometry (MS) of the compound showed a signal for an $(\mathrm{M}+\mathrm{H})^{+}$at $\mathrm{m} / z$ 595. The UV spectrum showed absorption maxima at 273 and $336 \mathrm{~nm}$, suggesting an apigenin chromophore (Mabry et al. 1970). The ${ }^{1} \mathrm{H}$ nuclear magnetic resonance (NMR) spectrum of the compound taken in methanol- $d_{4}$ showed the presence of six protons in the aromatic and alkene regions. The doublets at 6.91 and $7.83 \mathrm{ppm}$ (each $2 \mathrm{H}, J=8.9 \mathrm{~Hz}$ ) indicated the presence of a 1,4-disubstituted benzene moiety. Two singlet protons were observed at 6.39 and $6.55 \mathrm{ppm}$. The signals from 2.8 to $4.8 \mathrm{ppm}$ suggested the presence of diglycosyl sugar moiety (Harborne 1994). Taken together, the compound is suggested to be a diglycosyl conjugate of apigenin.

The compound was found by HPLC analysis to be present also in melon shoots at much greater amounts than in roots. The amount of the compound in shoots was estimated to be approximately $300 \mu \mathrm{g} / \mathrm{g}$ fresh wt on the basis of the HPLC data. The spectral data of the compound isolated from shoots were identical to the data from the compounds isolated from roots. Final structure elucidation for the apigenin diglycoside were made on the basis of 1D and 2D NMR data taken in dimethyl$d_{6}$ sulfoxide + deuterium oxide as a solvent $\left({ }^{1} \mathrm{H}-{ }^{1} \mathrm{H}\right.$ correlation spectroscopy [COSY], ${ }^{1} \mathrm{H}$-detected heteronuclear single quantum coherence [HSQC], ${ }^{1} \mathrm{H}$-detected heteronuclear multiple bond connectivity [HMBC], and nuclear Overhauser effect spectroscopy [NOESY]) together with UV and MS spectral data. Figure 2 shows the correlations observed in the ${ }^{1} \mathrm{H}-{ }^{1} \mathrm{H}$ COSY and $\mathrm{HMBC}$ spectra. A sugar anomeric proton signal at $\delta_{\mathrm{H}} 4.65$ $(J=9.8 \mathrm{~Hz})$ had long-range correlations in the HMBC experiment with the aromatic carbons at $\delta_{\mathrm{C}} 107.9,160.5$, and 163.4 each assigned to C-6, C-5, and C-7, respectively. This indicated that the first sugar is attached as $C$ - $\beta$-glycoside to the $\mathrm{C}-6$ position of the apigenin moiety. Downfield shift of the carbon signal of $C-2^{\prime \prime}\left(\delta_{\mathrm{C}} 80.8\right)$ suggested that the second sugar is attached to the $\mathrm{C}-2$ position of the first sugar. The second sugar anomeric carbon signal at $\delta_{\mathrm{C}} 105.2\left(\delta_{\mathrm{H}} 4.17\right)$ suggested the second sugar to be an $O$-glycoside. The NOESY correlations of $\mathrm{H}-\mathrm{1}^{\prime \prime}$ with $\mathrm{H}-3^{\prime \prime}$ and $\mathrm{H}-5^{\prime \prime}$ and of $\mathrm{H}-\mathrm{1}^{\prime \prime \prime}$ with $\mathrm{H}-3^{\prime \prime \prime}$ and $\mathrm{H}-5^{\prime \prime \prime}$ observed for each glycosyl moiety indicated that both of the glycosyl units are $\beta$-glucopyranosides. Thus, the structure of the compound was determined to be apigenin $6-C$ - $\beta$-glucopyranosyl $(1 \rightarrow 2)-O$ - $\beta$-glucopyranoside, i.e., isovitexin $2^{\prime \prime}-O$ $\beta$-glucoside (IG) (Fig. 3). This was in good agreement with the ${ }^{13} \mathrm{C}$ NMR data reported previously in the literature (Li et al. 1991).

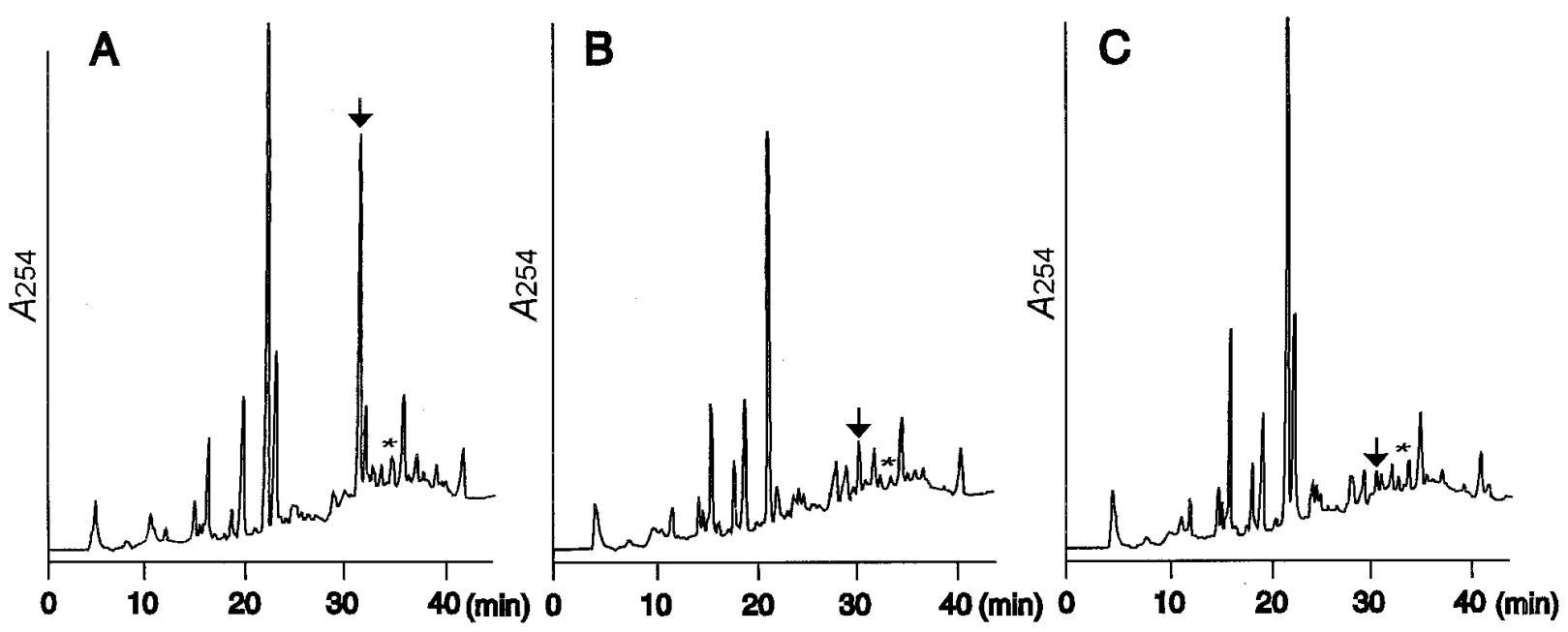

Fig. 1. High-performance liquid chromatography (HPLC) profiles of butanol extracts from melon roots detected at $254 \mathrm{~nm}$. A, Control; B, Glomus caledonium-inoculated; and $\mathbf{C}$, high-phosphate-supplemented roots were extracted at 40 days postinoculation and subjected to HPLC analysis. The peak ( $\rightarrow$ ) indicates a phosphate deficiency-induced compound in melon roots, and the corresponding compound was identified to be isovitexin $2^{\prime \prime}-O-\beta$-glucoside by spectroscopic methods. The peak (*) indicates isovitexin, a direct precursor of isovitexin $2^{\prime \prime}-O$ - $\beta$-glucoside biosynthesis. 
Time course of the accumulation of IG in melon roots.

Figure 4 shows the accumulation patterns of IG in melon roots. The levels of the flavonoid showed no significant difference among control, phosphate-supplemented, and inoculated roots at early stages of colonization. The levels were very low in all the roots $(0.2$ to $0.4 \mu \mathrm{g} / \mathrm{g}$ fresh wt). The compound started to accumulate at 30 days postinoculation and reached $3.3 \mu \mathrm{g} / \mathrm{g}$ fresh wt at 40 days postinoculation in control roots. In contrast, the levels of IG in mycorrhizal roots and phosphate-supplemented roots were similar to those at early stages of colonization (less than $0.5 \mu \mathrm{g} / \mathrm{g}$ fresh wt). These findings suggested that the accumulation of IG in control roots was caused by a phosphate deficiency.

The levels of isovitexin, the direct precursor in IG biosynthesis, were very low in control, phosphate-supplemented, and mycorrhizal roots (Fig. 1). No significant differences were observed among these roots at all the sampling points (data not shown).

\section{Mycorrhizal-colonization-stimulating activity of IG.}

Figure 5 shows the effect of IG on melon root colonization by the AM fungus $G$. caledonium under low $(0.05 \mathrm{mM})$ and high $(2 \mathrm{mM})$ phosphate conditions. At 25 days postinoculation, the compound concentration-dependently stimulated mycorrhizal colonization in roots grown under low phosphate conditions, whereas no stimulation was observed in roots grown under high phosphate conditions. At 45 days postinoculation, the degree of mycorrhizal colonization in control roots grown under high phosphate conditions $(8.8 \%)$ was much lower than when grown under low phosphate conditions $(22 \%)$. The treatment of roots with IG at concentrations of 20 and $50 \mu \mathrm{M}$ increased root colonization under both low and high phosphate conditions. In particular, the degrees of mycorrhizal colonization in treated roots grown under high phosphate conditions ( 25 and $22 \%$ at 20 and $50 \mu \mathrm{M}$, respectively) were comparable to that in untreated control roots grown under low phosphate conditions $(22 \%)$. There was no marked difference in growth among control and IG-treated (20 and 50 $\mu \mathrm{M})$ plants grown under high phosphate conditions throughout the experiments, while the growth of control plants grown under low phosphate conditions was slightly retarded at 45 days postinoculation.

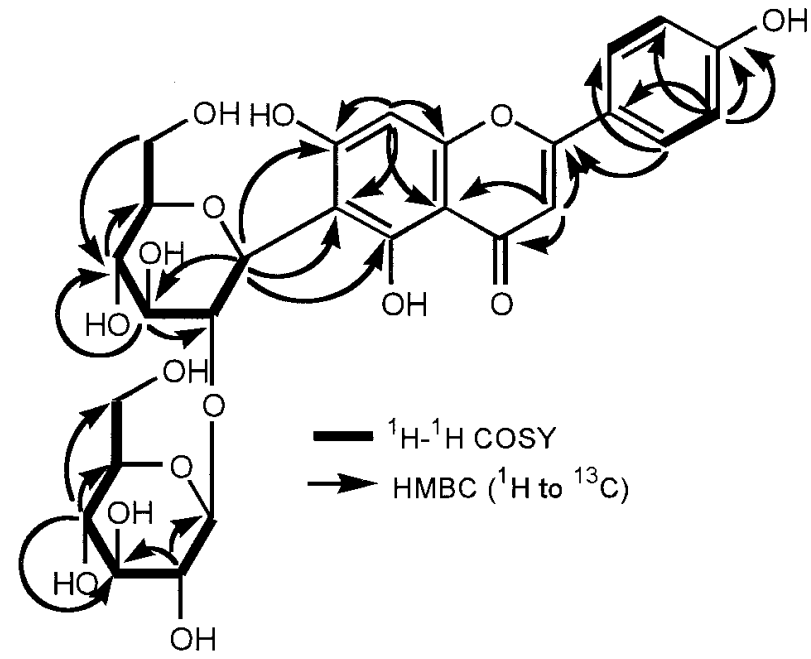

Fig. 2. Two-dimensional nuclear magnetic resonance analysis of the phosphate deficiency-induced compound isolated from melon shoots. Only key correlations observed in the ${ }^{1} \mathrm{H}-{ }^{1} \mathrm{H}$ correlation spectroscopy (COSY) and ${ }^{1} \mathrm{H}$-detected heteronuclear multiple bond connectivity (HMBC) spectra are shown.
The levels of IG in control and IG $(20 \mu \mathrm{M})$-treated roots at 45 days postinoculation in the experiments above were measured by HPLC analysis. The levels of the flavonoid glucoside in IG-applied roots were lower than those in control roots in both low and high phosphate conditions (Table 1).

The levels of IG in roots at 3 days after external application of the flavonoid solution were examined by HPLC using 3week-old melon plants grown in the presence of the AM fungus under low or high phosphate conditions. Application of IG solution at $20 \mu \mathrm{M}$ resulted in 2.3- and 1.7-fold increases in IGapplied roots compared with those in control roots grown under low and high phosphate conditions, respectively (Table 2).

\section{DISCUSSION}

There have been many reports on the effects of nutrient deficiency on secondary metabolite biosynthesis in plants. Phosphorus deficiency, nitrogen deficiency, or both, is reported to be one stress factor that enhances flavonoid content in many plants (Bongue-Bartelsman and Phillips 1995; Morandi and Le Quere 1991). The current study showed that the level of a $C$ glycosylflavone, identified as isovitexin $2^{\prime \prime}-O-\beta$-glucoside, significantly increased in melon roots grown under phosphatelimited conditions. Although there were small differences in the levels of several compounds contained in their butanol extracts during time course experiments among control, mycorrhizal, and phosphate-supplemented roots, IG was the only compound that showed such a dramatic increase upon phosphate deficiency in the experimental conditions employed here. Its accumulation closely correlated with the growth retardation of control plants observed from 30 days postinoculation. The level of the flavonoid in control roots was approximately sevenfold higher than that in mycorrhizal or phosphate-supplemented roots at 40 days postinoculation.

The mechanism for the accumulation of IG in melon roots upon phosphate deficiency is unknown. The compound was first isolated from the leaf methanol extracts of Gentiana asclepiadea (Goetz et al. 1976) and has been isolated from various plant species so far. The flavonoid was also found in the leaves of cucumber, which belongs to the same genus as melon (Krauze-Baranowska and Cisowski 2001). It was shown that 6$C$-glucosylflavones, including isovitexin, the direct precursor of IG, are synthesized by a $C$-glucosyltransferase that catalyses the transfer of glucose from UDP-glucose or ADP-glucose to 2-hydroxyflavanones at the C-6 position. It was also shown

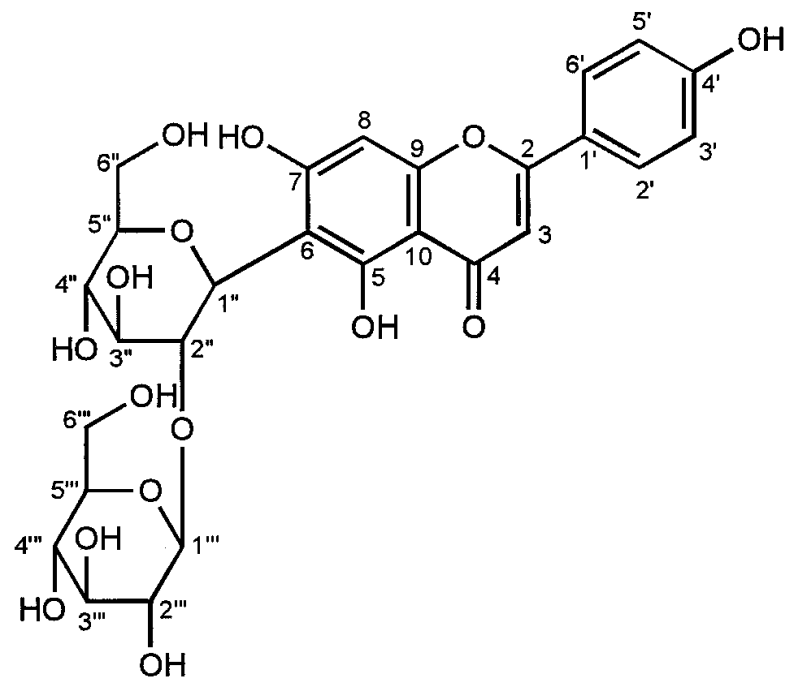

Fig. 3. Chemical structure of isovitexin $2^{\prime \prime}-O-\beta$-glucoside. 
that the flavone apigenin, an aglycone moiety of isovitexin and IG, could not act as a glucosyl acceptor in $C$-glucosylflavonoid synthesis (Kerscher and Franz 1987). IG is synthesized by following $2^{\prime \prime}$-O-glucosylation of isovitexin (Heinsbroek et al. 1980). In this study, the levels of the precursor isovitexin were very low in control, phosphate-supplemented, and mycorrhizal roots, and there were no significant differences among these roots at all the sampling points. IG was isolated from shoot butanol extracts at a much greater quantity than from root extracts. The HPLC analysis of each of the butanol extracts showed that the amount of the flavonoid in shoots (approximately $300 \mu \mathrm{g} / \mathrm{g}$ fresh wt) was approximately 100 to 150 times larger than that in roots (approximately 2 to $3 \mu \mathrm{g} / \mathrm{g}$ fresh wt). These facts suggest that IG is predominantly synthesized in shoots rather than roots of melon plants. It could be assumed that the flavonoid glucoside is synthesized de novo in roots or is translocated from shoots to roots by long-distance phloem transport upon phosphate deficiency.

The levels of IG were very low in mycorrhizal roots throughout the time course experiments. It has been shown that AM fungal colonization induces significant changes in the levels of flavonoid secondary metabolites in plant roots (Guenoune et al. 2001; Harrison and Dixon 1993; Morandi and Le Quere 1991). From the data presented in the earlier papers, it can be suggested that the reduced levels of IG in AM fungus-inoculated roots are due to (i) the improvement of phosphate nutrition in melon plants through the AM symbiosis, as suggested by the growth of mycorrhizal plants comparable to that of phosphate-supplemented plants; (ii) metabolism of the compound by the mycorrhizal fungus during root colonization; and (iii) suppression of the $C$-glycosylflavone biosynthesis, as observed for defense-related isoflavonoid compounds.

IG was found to stimulate arbuscular mycorrhiza formation under both low and high phosphate conditions. It was shown that root exudates and various flavonoids released from plant roots promote AM spore germination and hyphal growth in vitro (Bécard et al. 1992; Gianinazzi-Pearson et al. 1989; Nair et al. 1991; Poulin et al. 1993; Tsai and Phillips 1991). IG was tested for mycorrhizal-colonization-stimulating activity in melon roots since, among these AM fungal growth-promoting flavonoids, the isoflavonoids formononetin and biochanin A isolated from phosphate-deprived clover roots as well as a flavone apigenin, the aglycone of IG, also promote root colonization by AM fungi (Gianinazzi-Pearson et al. 1989; Nair et al. 1991; Siqueira et al. 1991; Xie et al. 1995). The mechanism for the enhanced colonization by the AM fungal growth-promoting flavonoids is unclear. It could be assumed that these flavonoids exuded from roots act as stimulators for AM fungal growth, thus helping to ensure contact with the root and establishment of the symbiosis. Further investigations are in progress to examine a stimulatory activity of the $C$-glycosylflavone on AM fungal growth and exudation of the compound from melon roots, which were not investigated in this study.

It was shown that the infection and intraradical growth of AM fungi are markedly inhibited in plant roots grown under high phosphate conditions, possibly through phosphate-mediated physiological alterations of the roots (Koide and Li 1990). Induction of plant defense genes in the roots is suggested to be one factor in reducing colonization in soil containing high phosphate concentrations (Guenoune et al. 2001; Lambais and Mehdy 1993). The high phosphate-mediated inhibition of mycorrhizal colonization was also observed in this study. The colonization rate in roots grown under high phosphate conditions was reduced by $60 \%$ in comparison to when grown under low phosphate conditions at 45 days postinoculation. Under these conditions, application of IG at 20 and $50 \mu \mathrm{M}$ increased root colonization by $G$. caledonium to the levels comparable to those in control roots grown under low phosphate conditions. The result suggests that the flavonoid glucoside might suppress the high-phosphate-mediated inhibition of mycorrhizal colonization in melon roots, thus making the plants susceptible to AM fungal infection and intraradical growth. A locally induced oxidative burst, one of the most powerful defense measure of plants against a microorganism (Lamb and Dixon 1997), is thought to limit the intracellular spread of the AM fungus $G$. intraradices in M. truncatula roots (Salzer et al. 1999). IG, isolated from ethanol extracts of barley leaves, was shown to have an antioxidative activity almost equivalent to that of $\alpha$-tocopherol (Osawa et al. 1992). The compounds capable of trapping $\mathrm{H}_{2} \mathrm{O}_{2}$, including 2,5-dihydroxycinnamic acid methyl ester and dimethylthiourea, blocked the induction of glutathion $\mathrm{S}$ transferase transcripts, the gene involved in plant hypersensitive disease resistance response, by a fungus-derived glucan elicitor (Levine et al. 1994). IG might suppress the plant defense system by scavenging active oxygen species such as $\mathrm{O}_{2}^{-}$ and $\mathrm{H}_{2} \mathrm{O}_{2}$ during the infection and intracellular growth of AM fungi in plant roots. Although the levels of IG in IG-applied roots were lower than those in control roots at 45 days postinoculation, probably because of the mycorrhizal-colonizationmediated decrease as discussed above, in the independent experiments using 3-week-old plants, the levels in IG-applied roots were higher than those in control roots at 3 days after application. This suggests that externally applied IG could cause the transient increase of IG levels in roots, thus stimulating mycorrhiza formation by the putative mechanisms discussed above. This also let us speculate that IG accumulated in phosphate-limited roots might act as a stimulator for root colonization by AM fungi upon phosphate starvation. However, it cannot be concluded from the data that IG was actually incorporated into the roots in the experiments. Direct incorporation of IG can be demonstrated by using (radio)labeled IG, for example, in order to trace externally applied IG in roots. Further investigations are needed to elucidate the mechanism of IG-mediated stimulation of mycorrhizal colonization.

It is known that flavonoid aglycones are sequestered inside cellular organelles, such as vacuoles, as their glycosylated forms and released from vacuoles by glycosidases as the actual

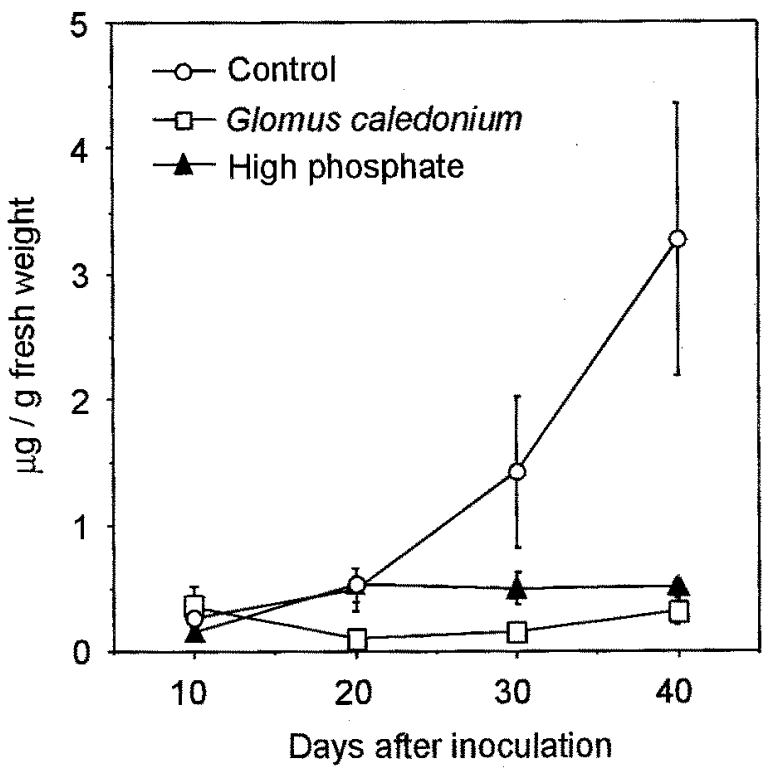

Fig. 4. Accumulation patterns of isovitexin $2^{\prime \prime}-O-\beta$-glucoside in control, Glomus caledonium-inoculated, and high-phosphate-supplemented melon roots. Data are the mean values \pm standard deviation for three replicates of one plant each. 
active compounds (Kessmann et al. 1990). The release of apigenin aglycone, which showed a mycorrhiza formation-stimulating activity (Xie et al. 1995), from IG seems to be unlikely in melon roots because the $\mathrm{C}-\mathrm{C}$ bond between the aromatic ring of apigenin aglycone and the first glucose residue is resistant to hydrolysis. However, since the experiments in this study were conducted with AM inocula containing rhizospheric bacteria under nonaxenic conditions, the possibility that the rhizospheric bacteria could cleave the $\mathrm{C}-\mathrm{C}$ bond to release the active apigenin aglycone or unidentified active degradation products from the $C$-glycosylflavone cannot be excluded. Rhizospheric bacteria belonging to the genera Rhizobium and Pseudomonas were shown to degrade various flavonoids via A- or C-ring fission mechanisms into phenolic compounds including phenylpropanoids (Rao and Cooper 1994).

In summary, the current study showed that a $C$-glycosylflavone identified as isovitexin $2^{\prime \prime}-O-\beta$-glucoside was significantly accumulated in melon roots upon phosphate deficiency and that the flavonoid stimulated arbuscular mycorrhiza formation in melon roots under low and high phosphate conditions. This is the first report on the possible involvement of $C$-glycosylflavonoids in AM symbiosis. Although flavonoids were shown to be unnecessary plant signal compounds in AM symbiosis (Bécard et al. 1995), a substantial amount of evidence indicates the involvement of flavonoids in the development and regulation of AM symbiosis (Harrison 1999; Vierheilig et al. 1998). To further address the significance of changes in IG levels, we are now examining the relationships between melon cultivar differences in AM colonization and IG levels in their roots and shoots. Further investigation may provide new insights to elucidate the flavonoid-mediated regulation involved in AM symbiosis.

\section{MATERIALS AND METHODS}

\section{Plant growth and mycorrhizal colonization.}

Surface-sterilized (2\% sodium hypochlorite solution, $10 \mathrm{~min}$ ), pregerminated seeds of melon (Cucumis melo L. cv. Newmelon) were planted in $38-\mathrm{ml}$ glass tubes $(\phi 2.2 \times 10 \mathrm{~cm})$ filled with heat-sterilized $\left(150^{\circ} \mathrm{C}, 1 \mathrm{~h}\right)$ light stone (average diameter approximately $3 \mathrm{~mm}$ ) and river sand mixture (1:2) (one plant per tube). For mycorrhizal fungus colonization, $2 \mathrm{~g}$ of a soil

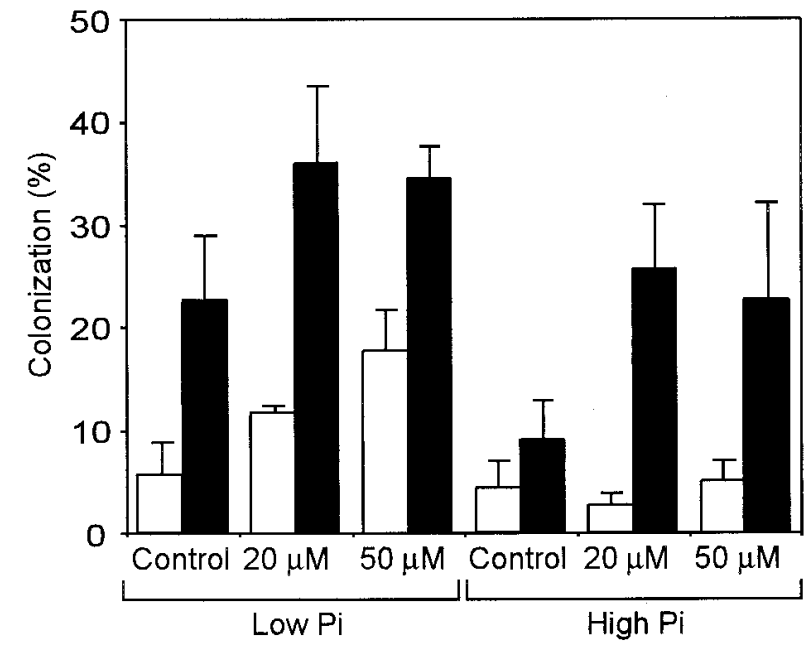

Fig. 5. Effects of isovitexin $2^{\prime \prime}-O-\beta$-glucoside $(20$ and $50 \mu \mathrm{M})$ on melon root colonization by Glomus caledonium under low $(0.05 \mathrm{mM})$ and high ( $2 \mathrm{mM})$ phosphate conditions. The degrees of mycorrhizal colonization in melon roots were evaluated at $25(\square)$ and $45(\square)$ days postinoculation. Data are the mean values \pm standard error for five replicates of one plant each. inoculum containing spores and hyphae of G. caledonium (Nicolson \& Gerdemann) Trappe \& Gerdemann (kindly provided by Akihiko Narutaki, Idemitsu Kosan Co., Ltd., Tokyo, Japan) was mixed through the tubes prior to planting. In order to produce an initially similar population of soil microbes in all treatments, $2 \mathrm{~g}$ of the soil inoculum was mixed with $4 \mathrm{ml}$ of water and passed through a $53-\mu \mathrm{m}$ soil sieve, and the sievates containing accompanying soil microbes but no mycorrhizal fungal spores and hyphae were added to the control tubes. The tubes were covered with aluminum foil to exclude light from the roots. After the pregerminated seeds were planted, all the tubes received $8 \mathrm{ml}$ of $1 / 2 \times$ Hoagland solution ( $\mathrm{pH} \mathrm{6.0)} \mathrm{(Arnon}$ and Hoagland 1940) containing $0.05 \mathrm{mM} \mathrm{KH}_{2} \mathrm{PO}_{4}$ and were watered with $5 \mathrm{ml}$ of the solution once a week. In experiments to assess the effects of phosphate on the accumulation of flavonoids in roots, the phosphate-supplemented plants were watered with $1 / 2 \times$ Hoagland solution containing $0.5 \mathrm{mM} \mathrm{KH}_{2} \mathrm{PO}_{4}$. Plants were maintained in a growth cabinet with a 16-h-day/ 8 -h-night cycle at $25 / 22^{\circ} \mathrm{C}$. Light intensity was $100 \mu \mathrm{E} \mathrm{m}^{-2} \mathrm{~s}^{-1}$. For assessment of mycorrhizal colonization, root samples were cleared in $10 \% \mathrm{KOH}$ and stained with $0.05 \%$ trypan blue in lactoglycerol (Phillips and Hayman 1970), and the degree of colonization was determined microscopically (McGonigle et al. 1990). The experiments were performed four times, with similar results each time.

\section{HPLC analysis.}

At each harvest, one tube from each treatment was collected to serve as one replicate. Freshly harvested roots were washed with water, weighed, and then extracted in $4 \mathrm{ml}$ of methanol by sonication for $30 \mathrm{~min}$. The methanol extract was concentrated in vacuo, the residue was first partitioned three times between ethyl acetate and water $(2 \mathrm{ml}$ each $)$, and then the residual water layer was further extracted with $2 \mathrm{ml}$ of water-saturated $n$-butanol three times. After evaporation, the butanol extract was dissolved in 400 to $700 \mu \mathrm{l}$ of $50 \%$ methanol-water, and a $10-\mu \mathrm{l}$ aliquot was subjected to HPLC analysis.

HPLC separations were performed on an Inertsil ODS column $(\phi 4.6 \times 250 \mathrm{~mm}, 5 \mu \mathrm{m}$; GL Sciences, Tokyo, Japan), and a linear gradient elution was applied at a flow rate of $0.8 \mathrm{ml} / \mathrm{min}$ within $30 \mathrm{~min}$ from water containing $0.1 \%$ acetic acid to $30 \%$ acetonitrile, followed by isocratic elution with $30 \%$ acetonitrile

Table 1. Levels of isovitexin $2^{\prime \prime}-O$ - $\beta$-glucoside (IG) in control and IGapplied roots at 45 days postinoculation ${ }^{\mathrm{a}}$

\begin{tabular}{lcc}
\hline Roots & Low phosphate & High phosphate \\
\hline Control & $0.9 \pm 0.3$ & $0.5 \pm 0.2$ \\
IG $20 \mu \mathrm{M}$ & $0.4 \pm 0.2$ & $0.2 \pm 0.1$ \\
IG $50 \mu \mathrm{M}$ & n.d. & n.d. \\
\hline
\end{tabular}

${ }^{\mathrm{a}}$ Levels are for the effects of IG $(20$ and $50 \mu \mathrm{M})$ on melon root colonization by Glomus caledonium under low $(0.05 \mathrm{mM})$ and high $(2 \mathrm{mM})$ phosphate conditions, as shown in Figure 5. Data are the mean values \pm standard error $(\mu \mathrm{g} / \mathrm{g}$ fresh $\mathrm{wt})$ for five replicates of one plant each.

${ }^{\mathrm{b}}$ Not determined.

Table 2. Levels of isovitexin $2^{\prime \prime}$ - $O$ - $\beta$-glucoside (IG) in 3-week-old mycorrhizal roots at 3 days after application of IG solution $(20 \mu \mathrm{M})^{\mathrm{a}}$

\begin{tabular}{lcc}
\hline Roots & Low phosphate & High phosphate \\
\hline Control & $0.7 \pm 0.2$ & $0.6 \pm 0.3$ \\
IG $20 \mu \mathrm{M}$ & $1.6 \pm 0.3$ & $1.0 \pm 0.1$ \\
\hline
\end{tabular}

${ }^{a}$ Levels of IG in roots at 3 days after application of IG solution were measured by high-performance liquid chromatography using 3-weekold plants in the presence of Glomus caledonium under low $(0.05 \mathrm{mM})$ and high $(2 \mathrm{mM})$ phosphate conditions. Data are the mean values \pm standard error $(\mu \mathrm{g} / \mathrm{g}$ fresh $\mathrm{wt})$ for four replicates of one plant each. 
for $5 \mathrm{~min}$. The column was further eluted by a linear gradient from 30 to $50 \%$ acetonitrile within $10 \mathrm{~min}$. Compounds eluting from the column were monitored at $254 \mathrm{~nm}$. Quantification of IG was determined from the peak area of the sample with reference to the calibration of the isolated compound. Each value is the mean \pm standard deviation from three replicates of one plant each. Isovitexin was prepared by $\mathrm{HCl}$ hydrolysis of IG and was identified by ${ }^{1} \mathrm{H}$ NMR spectroscopic analysis.

\section{Isolation of IG from melon roots and shoots.}

Surface-sterilized, pregerminated seeds of melon were planted on heat-sterilized light stone and river sand mixture (1:2) in 7-liter plastic trays. After the pregerminated seeds were planted, the trays received 1.5 liters of $1 / 2 \times$ Hoagland solution

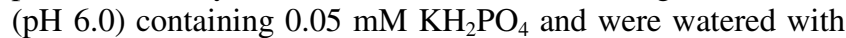
the solution once a week. The plants were grown in a growth cabinet for 6 weeks under the same conditions described above. Melon roots (approximately $400 \mathrm{~g}$ ) from 367 plants were washed and then transferred to 2 liters of methanol and allowed to stand for 2 days. The methanol extract was evaporated to give a thick aqueous solution (approximately $100 \mathrm{ml}$ ) and was then successively partitioned with ethyl acetate and water-saturated $n$-butanol (100 $\mathrm{ml} \times$ three times each). The butanol phase was evaporated to dryness, providing $316 \mathrm{mg}$ of a crude extract. The extract was chromatographed on a Chromatorex ODS column (Fuji Silysia Chemical Ltd., Aichi, Japan) eluted stepwise with solvents from water through $70 \%$ methanol. The fraction eluted with $50 \%$ methanol $(6.5 \mathrm{mg})$ was chromatographed on an Inertsil ODS HPLC column $(\phi 10 \times 250 \mathrm{~mm}$, $5 \mu \mathrm{m}$ ) employing a linear gradient elution within $30 \mathrm{~min}$ from water to $30 \%$ acetonitrile, followed by isocratic elusion with $30 \%$ acetonitrile for $5 \mathrm{~min}$ at a flow rate of $4.0 \mathrm{ml} / \mathrm{min}$. Compounds eluting from the column were monitored at $254 \mathrm{~nm}$. IG $(0.5 \mathrm{mg})$ eluted as a single peak at $30 \mathrm{~min}$ was collected.

Melon shoots obtained above (approximately $800 \mathrm{~g}$ ) were extracted and partitioned in the same way described above. The butanol extract $(2.7 \mathrm{~g})$ was chromatographed on a Chromatorex ODS column eluted stepwise with solvents from water through $70 \%$ methanol. The fractions eluted with 40 and $50 \%$ methanol contained IG. The $40 \%$ methanol eluate $(514 \mathrm{mg})$ was further purified by a Sephadex LH-20 column employing a isocratic elution with $50 \%$ methanol- $\mathrm{H}_{2} \mathrm{O}$ to afford IG $(75 \mathrm{mg})$. The purity of isovitexin glucoside was $96.2 \%$ as estimated from the peak area in the ${ }^{1} \mathrm{H}$ NMR spectrum. Signals of three minor contaminated compounds were also detected in the purified sample by ${ }^{1} \mathrm{H}$ NMR analysis. The molar ratio of the four compounds including isovitexin glucoside in the sample was calculated to be $96.2: 2.3: 0.8: 0.7$ by the comparison of the peak area of each compound.

\section{Identification of IG by spectroscopic methods.}

${ }^{1} \mathrm{H}$ and ${ }^{13} \mathrm{C}$ NMR spectra were obtained with a JNM-A500 NMR spectrometer (JEOL, Tokyo, Japan). The chemical shifts were referenced to the solvent peaks (dimethyl- $d_{6}$ sulfoxide $\delta_{\mathrm{H}}$ $2.49, \delta_{\mathrm{C}} 39.5$; methanol- $\left.d_{4} \delta_{\mathrm{H}} 3.30, \delta_{\mathrm{C}} 49.0\right)$ as an internal standard. UV spectra were measured with a U-3210 instrument (Hitachi High-Technologies, Tokyo, Japan). Mass spectra were recorded with a JEOL JMS-DX300 instrument.

${ }^{1} \mathrm{H}$ NMR $\left(500 \mathrm{MHz}\right.$, dimethyl- $d_{6}$ sulfoxide + deuterium oxide): $\delta 2.65\left(1 \mathrm{H}\right.$, br.s, H-5"') $2.85\left(1 \mathrm{H}, \mathrm{t}, J=8.9 \mathrm{~Hz}, \mathrm{H}-2^{\prime \prime \prime}\right)$, $2.97\left(1 \mathrm{H}, \mathrm{t}, J=8.9 \mathrm{~Hz}, \mathrm{H}-4^{\prime \prime \prime}\right), 3.05\left(1 \mathrm{H}, \mathrm{t}, J=8.9 \mathrm{~Hz}, \mathrm{H}-3^{\prime \prime \prime}\right)$, 3.17 (2H, m, H-6"'), 3.19 (1H, m, H-4"), 3.19 (1H, m, H-5"), $3.45\left(1 \mathrm{H}, \mathrm{m}, \mathrm{H}-6 \mathrm{a}^{\prime \prime}\right), 3.45\left(1 \mathrm{H}, \mathrm{m}, \mathrm{H}-3^{\prime \prime}\right), 3.65(1 \mathrm{H}, \mathrm{d}, J=11.6$ Hz, H-6b"), 4.17 (1H, br.s, H-1'"'), 4.37 (1H, br.s, H-2"), 4.65 $\left(1 \mathrm{H}, \mathrm{d}, J=9.8 \mathrm{~Hz}, \mathrm{H}-1^{\prime \prime}\right), 6.48(1 \mathrm{H}, \mathrm{s}, \mathrm{H}-8), 6.71(1 \mathrm{H}, \mathrm{s}, \mathrm{H}-3)$, $6.92\left(1 \mathrm{H}, \mathrm{d}, J=8.9 \mathrm{~Hz}, \mathrm{H}-3^{\prime}, 5^{\prime}\right), 7.88\left(1 \mathrm{H}, \mathrm{d}, J=8.9 \mathrm{~Hz}, \mathrm{H}-2^{\prime}\right.$, $\left.4{ }^{\prime}\right) .{ }^{13} \mathrm{C}$ NMR (125 MHz, dimethyl- $d_{6}$ sulfoxide + deuterium oxide): $\delta 163.4$ (C-2), 102.7 (C-3), 181.9 (C-4), 160.5 (C-5), 107.9 (C-6), 163.4 (C-7), 93.8 (C-8), 156.4 (C-9), 103.3 (C-10), $121.4\left(\mathrm{C}-1^{\prime}\right), 128.5\left(\mathrm{C}-2^{\prime}\right), 115.9\left(\mathrm{C}-3^{\prime}\right), 161.0\left(\mathrm{C}-4^{\prime}\right), 115.9$ $\left(\mathrm{C}-5^{\prime}\right), 128.5$ (C-6'), $71.1\left(\mathrm{C}-1^{\prime \prime}\right), 80.8\left(\mathrm{C}-2^{\prime \prime}\right), 78.3\left(\mathrm{C}-3^{\prime \prime}\right)$, $70.4\left(\mathrm{C}-4^{\prime \prime}\right), 81.5\left(\mathrm{C}-5^{\prime \prime}\right), 61.3\left(\mathrm{C}-6^{\prime \prime}\right), 105.2\left(\mathrm{C}-1^{\prime \prime \prime}\right), 74.6$

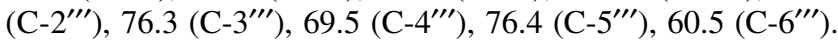
${ }^{13} \mathrm{C}$ NMR (125 MHz, methanol- $d_{4}$, sugar moiety only): $\delta 73.4$ $\left(\mathrm{C}-1^{\prime \prime}\right), 81.8$ (C-2'), $80.0\left(\mathrm{C}-3^{\prime \prime}\right), 71.6\left(\mathrm{C}-4^{\prime \prime}\right), 82.6$ (C-5"), $62.9\left(\mathrm{C}-6^{\prime \prime}\right), 106.2\left(\mathrm{C}-1^{\prime \prime \prime}\right), 76.0\left(\mathrm{C}-2^{\prime \prime \prime}\right), 77.6\left(\mathrm{C}-3^{\prime \prime \prime}\right), 70.9$ $\left(\mathrm{C}-4^{\prime \prime \prime}\right), 77.9\left(\mathrm{C}-5^{\prime \prime \prime}\right), 62.3$ (C-6"' $6^{\prime \prime \prime}$. (Li et al. 1991; $\delta 73.4\left[\mathrm{C}-1^{\prime \prime}\right]$,

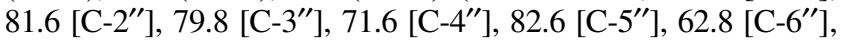
$106.0\left[\mathrm{C}-1^{\prime \prime \prime}\right], 75.9\left[\mathrm{C}-2^{\prime \prime \prime}\right], 77.4\left[\mathrm{C}-3^{\prime \prime \prime}\right], 71.1\left[\mathrm{C}-4^{\prime \prime \prime}\right], 77.8$ $\left[\mathrm{C}-5^{\prime \prime \prime}\right], 62.4$ [C-6"'] .) FAB MS m/z: $595(\mathrm{M}+\mathrm{H})^{+}$. UV $\lambda_{\max } \mathrm{nm}$ (methanol): 273, 336 .

\section{Test for mycorrhizal-colonization-stimulating activity in melon roots.}

Surface-sterilized, pregerminated seeds of melon (Cucumis melo L. cv. Newmelon) were planted on vermiculite mixed with $2 \mathrm{~g}$ of a soil inoculum of G. caledonium in 38-ml glass tubes $(\phi 2.2 \times 10 \mathrm{~cm})$. The tubes were covered with aluminum foil to exclude light. Prior to planting, $13 \mathrm{ml}$ of 20 or $50 \mu \mathrm{M}$ solutions of IG purified from shoots as described above were added into each tube. Ten milliliters of the solutions was again applied into the tubes at 25 days postinoculation. The flavonoid was first dissolved in a small volume of methanol and then transferred to $1 / 2 \times$ Hoagland solution $(\mathrm{pH} 6.0$ ) containing $0.05 \mathrm{mM}$

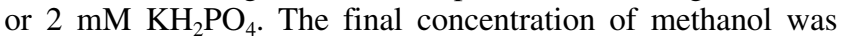
$0.3 \%$ (wt/wt). The control tubes received the Hoagland solutions containing the same concentration of methanol. Each tube was watered once a week with $5 \mathrm{ml}$ of the Hoagland solution

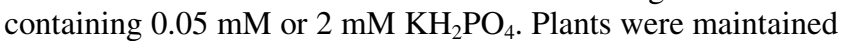
in a growth cabinet and the degree of mycorrhizal colonization was evaluated at 25 and 45 days postinoculation in the same way as described above. The experiments were performed with five plants per treatment and repeated at least twice, with similar results each time. The levels of IG in roots at 45 days postinoculation were examined by HPLC as described above.

In experiments to examine on the possible incorporation of IG into roots at shorter time points, melon plants were grown for 3 weeks in the presence of the AM fungus under the same conditions as described above but without the initial application of the flavonoid solution. Ten milliliters of $20-\mu \mathrm{M}$ IG solutions was applied into each tube, and IG levels in roots were measured at 3 days after application by HPLC as described above. The experiments were performed with four plants per treatment.

\section{ACKNOWLEDGMENTS}

The authors are very grateful to A. Narutaki, Idemitsu Kosan Co., Ltd., Tokyo, Japan, for supplying soil inocula of arbuscular mycorrhizal fungi. The authors also wish to thank N. Onodera for technical assistance. This work was supported by the Ministry of Education, Science, Sports and Culture, Grant-in-Aid to K. Akiyama for Encouragement of Young Scientists (A), No. 09760117, 1997-1998.

\section{LITERATURE CITED}

Akiyama, K., and Hayashi, H. Arbuscular mycorrhizal fungus-promoted accumulation of two new triterpenoids in cucumber roots. Biosci. Biotechnol. Biochem. In press.

Arnon, D. I., and Hoagland, D. R. 1940. Crop production in artificial culture solutions and in soils with special reference to factors influencing yields and absorption of inorganic nutrients. Soil Sci. 50:463-483.

Bécard, G., Douds, D. D., and Pfeffer, P. E. 1992. Extensive in vitro hyphal growth of vesicular-arbuscular mycorrhizal fungi in the presence of $\mathrm{CO}_{2}$ and flavonols. Appl. Environ. Microbiol. 58:821-825.

Bécard, G., Taylor, L. P., Douds, D. D., Jr., Pfeffer, P. E., and Doner, L. 
W. 1995. Flavonoids are not necessary plant signal compounds in arbuscular mycorrhizal symbioses. Mol. Plant-Microbe Interact. 8:252258.

Bongue-Bartelsman, M., and Phillips, D. A. 1995. Nitrogen stress regulates gene expression of enzymes in the flavonoid biosynthetic pathway of tomato. Plant Physiol. Biochem. 33:539-546.

Fester, T., Maier, W., and Strack, D. 1999. Accumulation of secondary compounds in barley and wheat roots in response to inoculation with an arbuscular mycorrhizal fungus and co-inoculation with rhizosphere bacteria. Mycorrhiza 8:241-246.

Gianinazzi-Pearson, V. 1996. Plant cell responses to arbuscular mycorrhizal fungi: Getting to the roots of the symbiosis. Plant Cell 8:18711883.

Gianinazzi-Pearson, V., Branzanti, B., and Gianinazzi, S. 1989. In vitro enhancement of spore germination and early hyphal growth of a vesicular-arbuscular mycorrhizal fungus by host root exudates and plant flavonoids. Symbiosis 7:243-255.

Goetz, M., Hostettmann, K., and Jacot-Guillarmod, A. 1976. A new Cglycosylflavone from Gentiana asclepiadea. Phytochemistry 15:2014.

Guenoune, D., Galili, S., Phillips, D. A., Volpin, H., Chet, I., Okon, Y., and Kapulnik, Y. 2001. The defense response elicited by the pathogen Rhizoctonia solani is suppressed by colonization of the AM-fungus Glomus intraradices. Plant Sci. 160:925-932.

Harborne, J. B., ed. 1994. The Flavonoids: Advances in Research Since 1986. 1st ed. Chapman \& Hall, London.

Harrison, M. J. 1999. Molecular and cellular aspects of the arbuscular mycorrhizal symbiosis. Annu. Rev. Plant Physiol. Plant Mol. Biol. 50: 361-389.

Harrison, M. J., and Dixon, R. A. 1993. Isoflavonoid accumulation and expression of defense gene transcripts during the establishment of vesicular-arbuscular mycorrhizal associations in roots of Medicago truncatula. Mol. Plant-Microbe Interact. 6:643-654.

Heinsbroek, R., Brederode, J. V., Nigtevecht, G. V., Maas, J., Kamsteeg, J., Besson, E., and Chopin, J. 1980. The $2^{\prime \prime}-O$-glucosylation of vitexin and isovitexin in petals of Silene alba is catalysed by two different enzymes. Phytochemistry 19:1935-1938.

Kerscher, F., and Franz, G. 1987. Biosynthesis of vitexin and isovitexin: Enzymatic synthesis of the $C$-glucosylflavones vitexin and isovitexin with an enzyme preparation from Fagopyrum esculentum M. seedlings. Z. Naturforsch. Sect. C Biosci. 42c:519-524.

Kessmann, H., Edwards, R., Geno, P. W., and Dixon, R. A. 1990. Stress responses in alfalfa (Medicago sativa L.). V. Constitutive and elicitorinduced accumulation of isoflavonoid conjugates in cell suspension cultures. Plant Physiol. 94:227-232.

Koide, R. T., and Li, M. 1990. On host regulation of the vesicular-arbuscular mycorrhizal symbiosis. New Phytol. 114:59-74.

Krauze-Baranowska, M., and Cisowski, W. 2001. Flavonoids from some species of the genus Cucumis. Biochem. Syst. Ecol. 29:321-324.

Lamb, C., and Dixon, R. A. 1997. The oxidative burst in plant disease resistance. Annu. Rev. Physiol. Plant Mol. Biol. 48:251-275.

Lambais, M. R., and Mehdy, M. C. 1993. Suppression of endochitinase $\beta$-1,3-endoglucanase, and chalcone isomerase expression in bean vesicular-arbuscular mycorrhizal roots under different soil phosphate conditions. Mol. Plant-Microbe Interact. 6:75-83.

Levine, A., Tenhaken, R., Dixon, R. A., and Lamb, C. 1994. $\mathrm{H}_{2} \mathrm{O}_{2}$ from the oxidative burst orchestrates the plant hypersensitive disease resis- tance response. Cell 79:583-593.

Li, Q. M., van den Heuvel, H., Delorenzo, O., Corthout, J., Pieters, L. A. Vlietinck, A. J., and Claeys, M. 1991. Mass spectral characterization of $C$-glycosidic flavonoids isolated from a medicinal plant (Passiflora incarnata). J. Chromatogr. 562:435-446.

Mabry, T. J., Markham, K. R., and Thomas, M. B. 1970. The Systematic Identification of Flavonoids. Springer-Verlag, New York.

McGonigle, T. P., Miller, M. H., Evans, D. G., Fairchild, G. L., and Swan, J. A. 1990. A new method which gives an objective measure of colonization of roots by vesicular-arbuscular mycorrhizal fungi. New Phytol 115:495-501.

Morandi, D., and Le Quere, J. L. 1991. Influence of nitrogen on accumulation of isosojagol (a newly detected coumestan in soybean) and associated isoflavonoids in roots and nodules of mycorrhizal and non-mycorrhizal soybean. New Phytol. 117:75-79.

Nair, M. G., Safir, G. R., and Siqueira, J. O. 1991. Isolation and identification of vesicular-arbuscular mycorrhiza-stimulatory compounds from clover (Trifolium repens) roots. Appl. Environ. Microbiol. 57: 434-439.

Osawa, T., Katsuzaki, H., Hagiwara, Y., Hagiwara, H., and Shibamoto, T. 1992. A novel antioxidant isolated from young green barley leaves. J. Agric. Food Chem. 40:1135-1138.

Phillips, J. M., and Hayman, D. S. 1970. Improved procedures for clearing roots and staining parasitic and vesicular-arbuscular mycorrhizal fungi for rapid assessment of infection. Trans. Br. Mycol. Soc. 55:158 161.

Poulin, M. J., Bel-Rhlid, R., Piché, Y., and Chênevert, R. 1993. Flavonoids released by carrot (Daucus carota) seedlings stimulate hyphal development of vesicular-arbuscular mycorrhizal fungi in the presence of optimal $\mathrm{CO}_{2}$ enrichment. J. Chem. Ecol. 19:2317-2327.

Rao, J. R., and Cooper, J. E. 1994. Rhizobia catabolize nod gene-inducing flavonoids via C-ring fission mechanisms. J. Bacteriol. 176:54095413.

Redecker, D., Kodner, R., and Graham, L. E. 2000. Glomalean fungi from the Ordovician. Science 289:1920-1921.

Salzer, P., Corbière, H., and Boller, T. 1999. Hydrogen peroxide accumulation in Medicago truncatula roots colonized by the arbuscular mycorrhiza-forming fungus Glomus intraradices. Planta 208:319325.

Siqueira, J. O., Safir, G. R., and Nair, M. G. 1991. Stimulation of vesicular-arbuscular mycorrhiza formation and growth of white clover by flavonoid compounds. New Phytol. 118:87-93.

Tsai, S. M., and Phillips, D. A. 1991. Flavonoids released naturally from alfalfa promote development of symbiotic Glomus spores in vitro. Appl. Environ. Microbiol. 57:1485-1488.

Vierheilig, H., Bago, B., Albrecht, C., Poulin, M. J., and Piche, Y. 1998. Flavonoids and arbuscular-mycorrhizal fungi. Adv. Exp. Med. Biol. 439:9-33.

Walter, M. H., Fester, T., and Strack, D. 2000. Arbuscular mycorrhizal fungi induce the non-mevalonate methylerythritol phosphate pathway of isoprenoid biosynthesis correlated with accumulation of the 'yellow pigment' and other apocarotenoids. Plant J. 21:571-578.

Xie, Z. P., Staehelin, C., Vierheilig, H., Wiemken, A., Jabbouri, S., Broughton, W. J., Vögeli-Lange, R., and Boller, T. 1995. Rhizobial nodulation factors stimulate mycorrhizal colonization of nodulating and non-nodulating soybeans. Plant Physiol. 108:1519-1525. 